\title{
Modifications of Liquid Electrolyte for Monolithic Dye-sensitized Solar Cells
}

\author{
Putri Nur Anggraini ${ }^{a *}$, Erlyta Septa Rosa ${ }^{a}$, Natalita Maulani Nursama, \\ Rico Fernando Sinaga ${ }^{\text {b }}$, Shobih ${ }^{a}$ \\ ${ }^{a}$ Research Center for Electronics and Telecommunication \\ Indonesian Institute of Sciences \\ Komplek LIPI Gedung 20 lantai 4, Jl Sangkuriang Cisitu \\ Bandung, Indonesia \\ ${ }^{b}$ Department of Physics Engineering \\ Telkom University \\ Jl. Telekomunikasi No. 1, Terusan Buah Batu, Sukapura, Dayeuh Kolot \\ Bandung, Indonesia
}

\begin{abstract}
Dye-sensitized solar cells (DSSC) has been well known as a highly competitive photovoltaic technology owing to its interesting characteristics, such as, low-cost, simple, and convenient to modify both chemically and physically. One way to reduce the production cost of DSSCs is to conduct a structural modification in the form of a monolithic structure by using a single conductive substrate to accommodate both photoelectrode and counter electrode. However, the photovoltaic performance of monolithic DSSCs is typically still lacking compared to its conventional DSSCs counterparts that uses sandwich structure. One of the crucial factors that determine the photovoltaic performance of a monolithic DSSC is its electrolyte. In this work, the performance of monolithic DSSCs were studied through modifications of the electrolyte component. Two types of commercial liquid electrolytes that have different chemical properties were used and combined into various compositions, and the resulting DSSCs performances were compared. The stability of the monolithic cells was also monitored by measuring the cells repeatedly under the same condition. The result showed that during the first measurement the highest performance with a power conversion efficiency of $1.69 \%$ was achieved by the cell with a higher viscosity electrolyte. Meanwhile, the most stable performance is shown by the cell containing lower viscosity electrolyte, which achieved an efficiency of $0.66 \%$ that measured on day 35 .
\end{abstract}

Keywords: DSSC, monolithic DSSC, liquid electrolyte, photoelectrode.

\section{INTRODUCTION}

Since the energy supply becomes one of the biggest issues in the world, experts have expedited their efforts to find alternative energy resources. It is even more challenging to develop sustainable yet harmless energy, on the contrary to fossil fuels as the largest energy source on earth. Nevertheless, researches related to renewable energy are still continuously conducted and one of the most promising technologies to produce such energy is the solar cell technology, which can convert light energy from the sun into electricity. A silicon-based solar cell is the first generation of the photovoltaic device that has recorded the photoconversion efficiency up to $26.7 \%$ [1]; however, it requires a considerable high manufacturing cost so that current photovoltaic researches have been significantly geared towards the discovery of more affordable devices.

During the initial research, Grätzel, et. al. had invented a low cost yet highly efficient dye sensitized solar cells (DSSCs) which yielded up to 7\% [2]. The preparation process was surprisingly very simple and clean, which released almost zero contaminants, and the

* Corresponding Author.

Received: November 28, 2020 ; Revised: February 16, 2021

Accepted: April 06, 2021 ; Published: August 31, 2021

Open access under CC-BY-NC-SA

(C) 2021 PPET - LIPI materials did not require high purity [3]. Thereafter, DSSCs became popular since it was identified as an environment-friendly and economical photovoltaic technology.

DSSCs generally consist of photoelectrode and counter electrode that are positioned in a sandwich configuration with electrolyte being injected in between those electrodes (Figure 1). The photoelectrode typically consists of a layer of nanocrystalline semiconductor oxide, mostly a $\mathrm{TiO}_{2}$, on a transparent conductive oxide (TCO)-layered glass substrate, which is then sensitized by a dye. A metal layer such as platinum or carbon is coated on another conductive substrate to prepare the counter electrode.

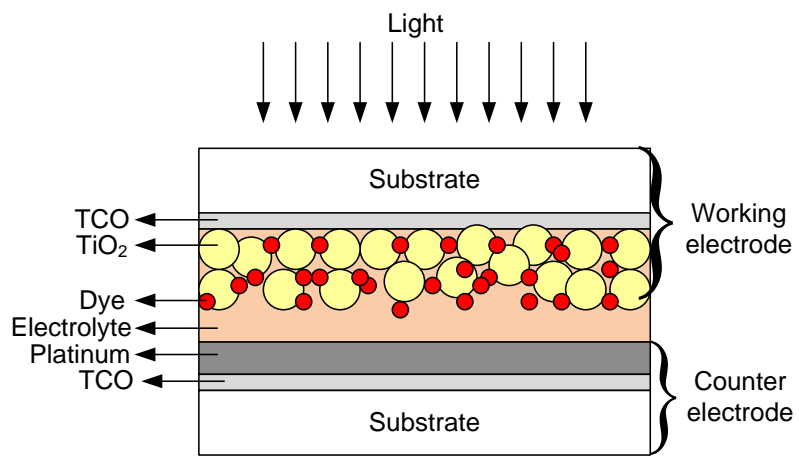

Figure 1. Configuration of a conventional sandwich-type DSSC. 
Several researchers have reported significant developments of DSSCs as the results of their efforts to optimize the photovoltaic performance, such as performing $\mathrm{TiCl}_{4}$ treatment [4], [5], adding blocking layer on the photoelectrode surface [6]-[8], and optimizing the sealing between the electrodes [9], [10]. Some interesting modifications have also been conducted to improve the applicability feature of DSSCs, such as fabricating flexible DSSCs [11] or up-scaling DSSCs into module [12]- [14]. Moreover, DSSCs have been involved in smart technology application such as selfpowered IoTs [15] and building integrated photovoltaic application (BIPV) [16]. However, one of the recent attractive development of DSSCs researches is the switching of DSSCs structure from a sandwich to a monolithic.

Monolithic DSSCs are prepared by eliminating the use of conductive substrate in the counter electrode component so that the device merely has a single conductive substrate. This strategy is an effective way to reduce the production cost of the DSSCs and minimize the preparation process. Consequently, a spacer such as a porous $\mathrm{ZrO}_{2}$ layer is required in monolithic DSSCs to separate the photoelectrode and counter electrode. It is also preferred to use liquid electrolyte in monolithic cell preparation since it was proven to successfully achieve an optimum outcome when used in conventional DSSCs [17].

As one of the crucial components in DSSCs, electrolyte is an interesting topic to investigate due to its key role in both of sandwich and monolithic DSSCs, particularly related to the reliability and durability of the devices. When employing a liquid electrolyte, it is important to consider the containing ingredients such as organic solvent, redox couple, and an electric additive, which give a significant influence on the photovoltaic performance [14], [15].

In this work, two types of commercial liquid electrolyte were applied in monolithic DSSCs. These electrolytes contain the same redox mediators (i.e. iodide/triiodide) with different types of solvent. One of the electrolytes contains acetonitrile $(\mathrm{AcN})$ and valetronitile ( $\mathrm{VN})$ as solvent, which are formulated to generate high performance solar cells that consequently yield high voltage and current. However, the contained solvent has a lower boiling point $\left(82{ }^{\circ} \mathrm{C}\right)$ [18] which causes weak stability of the device. Meanwhile, the other electrolyte has 3-methoxypropionitrile (MePN) as solvent that provides better chemical stability owing to its medium boiling point $\left(164{ }^{\circ} \mathrm{C}\right)$ [18] and allows a long life operating photovoltaic cell. These solvent-based electrolytes are frequently used in sandwich DSSCs which has been proven its remarkable efficiency and long-term solar device performance stability [19]. Reaction of the mixed solvent expectedly can yield certain properties complying with the excellent performance of each electrolytes which can work appropriately for a non-sandwich device. Accordingly, both electrolytes were mixed in various composition ratios to investigate the optimum characteristics, particularly for monolithic DSSCs. The stability of the devices was also studied by measuring the photovoltaic performance during a prolonged time interval.

\section{THE EXPERIMENTAL}

In this work, monolithic DSSCs were prepared on fluorine-doped tin oxide (FTO) substrates with a size of $2 \mathrm{~cm} \times 1.5 \mathrm{~cm}$ and sheet resistivity of $15 \mathrm{ohm} / \mathrm{sq}$ according the configuration shown in Figure 2. Substrate preparation was preceded by scribing the FTO glass in certain area to separate the side of the photoelectrode and counter electrode. The FTO glasses were then cleaned using an ultrasonic cleaner and rinsed in ethanol for 10 minutes before it was dried naturally.

Each layer illustrated on Figure 2 was deposited by screen printing technique. Figure 3 shows each pattern design for $\mathrm{TiO}_{2}, \mathrm{ZrO}_{2}$, and carbon layer with an area of $0.7 \mathrm{~cm} \times 1 \mathrm{~cm}, 0.7 \mathrm{~cm} \times 0.7 \mathrm{~cm}$, and $0.8 \mathrm{~cm} \times 0.5 \mathrm{~cm}$, respectively.

\section{A. Photoelectrode Preparation}

$\mathrm{TiO}_{2}$ commercial paste (Dyesol, DSL 18 NR-AO) was deposited onto cleaned FTO glass and was dried at $120{ }^{\circ} \mathrm{C}$ for $10 \mathrm{~min}$. The deposition process was applied twice and subsequently dried using a similar condition. The layer was then sintered by a furnace (Linberg) at 500 ${ }^{\circ} \mathrm{C}$ for 60 minutes. Post-treatment was applied to the $\mathrm{TiO}_{2}$ layer through immersion in the $\mathrm{TiCl}_{4}$ solution $(40 \mathrm{mM})$ at $70{ }^{\circ} \mathrm{C}$ for 30 minutes. After the drying process, $\mathrm{ZrO}_{2}$ commercial paste (Dyesol) was printed on the $\mathrm{TiO}_{2}$ layer and heated at $120{ }^{\circ} \mathrm{C}$ for 10 minutes. The $\mathrm{ZrO}_{2}$ layer deposition was applied twice and heated with a similar condition. The photoelectrode was then sintered at $500{ }^{\circ} \mathrm{C}$ for 60 minutes.

\section{B. Counter Electrode Preparation}

In this experiment, carbon composites containing graphite and amorphous carbon were used as catalyst materials in the counter electrode. First, carbon paste was prepared by mixing graphite $(1.5 \mathrm{~g})$, activated carbon (6 $\mathrm{g}), \mathrm{TiO}_{2}$ Degussa P25 (0.75 g), terpineol (12.75 g), and ethyl cellulose $(0.9 \mathrm{~g})$. The carbon paste was then coated onto the $\mathrm{ZrO}_{2}$ layer before it was dried at $120^{\circ} \mathrm{C}$ for 10 minutes and then sintered at a temperature of $400{ }^{\circ} \mathrm{C}$ for 45 minutes.

In the next process, the cells were immersed in a dye solution ( $0.02 \mathrm{~g} \mathrm{Z907}$ dye in $100 \mathrm{ml}$ ethanol) for 24 hours under dark condition. The cells were then rinsed with ethanol and dried.

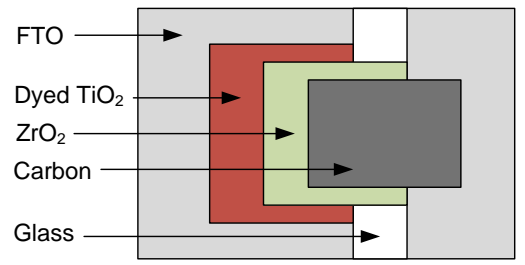

(a)

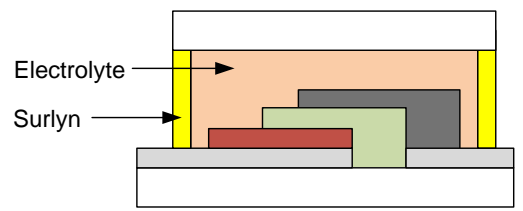

(b)

Figure 2. The geometrical structure of monolithic DSSCs in (a) top view and (b) cross-section view. 


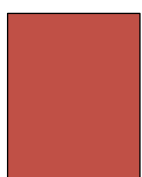

(a)

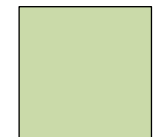

(b)

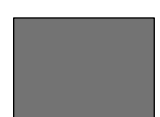

(c)
Figure 3. Pattern design for screen printing of (a) $\mathrm{TiO}_{2}$, (b) $\mathrm{ZrO}_{2}$, and (c) carbon layer.

\section{Assembly and Electrolyte Injection}

The dyed cells were assembled by covering the cells surface with non-conductive glasses and sealing them using thermoplastic surlyn. Three types of liquid electrolytes were prepared by mixing the commercial EL-HPE electrolyte type (Greatcell) and EL-HSE type (Greatcell) with the composition ratios according to Table 1. The liquid electrolyte was then injected into the cells through the tiny hole on the conductive glass surface.

\section{Cell Characterization}

To measure the photovoltaic parameters, all cells were characterized by illuminating each cell using a sun simulator with an AM1.5 filter whilst photoanode and cathode of each cell were connected to an I-V measurement system (National Instrument). These measurements were conducted six times at day 0 , day 4 , day 15 , day 22 , day 29 , and day 35 to investigate the stability of the cells. The cells were also characterized by an incident photon-to-current conversion efficiency (IPCE) to study the external quantum efficiency of the cells.

\section{RESULTS AND DISCUSSIONS}

Three compositions of the liquid electrolyte were used to study both the efficiency and stability of the monolithic DSSCs. As mentioned before, the experiment involved two types of commercial paste, namely EL-HPE and EL-HSE liquid electrolyte, which have different constituents due to their purposes. However, both electrolytes use iodide/triiodide as their redox couple. The characteristic of each liquid electrolyte is strongly affected by their solvent as the basic component. In this case, EL-HPE contains acetonitrile (AcN) and valeronitile (VN) as the solvent while EL-HSE contains 3-methoxypropionitrile (MePN) [20]. Table 2 lists the information of solvent properties including viscosity, dielectric constant, and donor number that could influence the performance of monolithic DSSCs.

The monolithic DSSCs were prepared with a certain geometrical structure that can be seen in Figure 2. $\mathrm{TiO}_{2}$ paste was printed onto FTO glass entirely without being crossed over the non-FTO area. The zirconia layer was directly deposited onto the dyed $\mathrm{TiO}_{2}$ layer partially and the remaining layers were crossed over to the non-FTO area.

TABLE 1. THE COMPOSITION RATIO OF LIQUID ELECTROLYTE.

\begin{tabular}{|c|c|c|}
\hline \multirow{2}{*}{ Sample } & \multicolumn{2}{|c|}{ Composition Ratios } \\
\cline { 2 - 3 } Cell A & EL-HPE & EL-HSE \\
\hline Cell B & 1 & 1 \\
\hline Cell C & 1 & 1 \\
\hline
\end{tabular}

For the counter electrode material, carbon was preferred since it showed better performance compared to platinum when used in monolithic DSSC according to our previous report [21]. Carbon was directly applied on the photoelectrode side, partially right on the $\mathrm{ZrO}_{2}$ layer and the remaining layers were crossed over the other FTO area. This step is significantly different from conventional DSSCs which the photoelectrode and counter electrode were prepared separately. The active area of the cell is determined by the area that encompasses all three layers of $\mathrm{TiO}_{2}, \mathrm{ZrO}_{2}$ and carbon. Herein, the active area of the monolithic cell was $0.7 \mathrm{~cm}^{2}$.

During the illumination of the monolithic cells, the data was processed to yield the quantitative photovoltaic parameters such as short circuit current density $\left(J_{s c}\right)$, open-circuit voltage $\left(V_{o c}\right)$, maximum power $\left(P_{\max }\right)$, fill factor $(F F)$, and photoconversion efficiency $(\eta)$. The efficiency was calculated by the following equation [22]:

$$
\eta=\frac{J_{s c} V_{o c} F F}{P_{\text {in }}}
$$

where $P_{i n}$ is denoted as the intensity of incident light. Meanwhile, the value of $F F$ was obtained by the following formula [22]:

$$
F F=\frac{P_{\max }}{J_{S c} V_{o c}}
$$

The I-V curves obtained from the I-V measurement are shown in Figure 4. All of the monolithic cells show a similar curve shape characteristic. The shape of the I-V curves, however, are clearly different from an ideal solar cell I-V characteristic curve that has a high maximum power point (MPP) due to the high fill factor value $(>0.5)$ under normal condition [23].

The photovoltaic parameters listed in Table 2 also confirms that the entire cells have small FF values in the first measurement (day 0), so that steep linear curves were obtained as a consequence. There are some factors that can be argued related to these results. First, the manual design of monolithic cells in planar architecture is likely considered as the cause of imperfect contact between the electrodes [21], which can contribute to charge recombination. The existence of spacer layer can also become the contributing factor for the low $V_{o c}$ value possibly due to its inappropriate thickness, which potentially could promote recombination between the photogenerated electrons in semiconductor and holes in the electrolyte [23]. Nevertheless, the photovoltaic activity for all cells have worked perfectly, with the highest efficiency exceeded $1.6 \%$. The highest power conversion efficiency reported in this work is higher than previous studies that used unmixed electrolyte [24], [19].

TABLE 2. PHYSICAL PARAMETERS OF SOLVENT USED FOR LIQUID

\begin{tabular}{|l|c|c|c|}
\hline \multicolumn{1}{|c|}{ Name } & Viscosity & $\begin{array}{c}\text { Dielectric } \\
\text { constant }\end{array}$ & $\begin{array}{c}\text { Donor } \\
\text { number }\end{array}$ \\
\hline Acetonitrile $(\mathrm{AcN})$ & $0.33\left(30^{\circ} \mathrm{C}\right)$ & 36 & 14.1 \\
\hline Valeronitile $(\mathrm{VN})$ & $0.78\left(19^{\circ} \mathrm{C}\right)$ & 21 & \\
\hline $\begin{array}{l}\text { Methoxypropionitrile } \\
\text { (MePN) }\end{array}$ & 2.5 & 36 & 16.1 \\
\hline
\end{tabular}


The results from repeated I-V measurements in six different times are summarized in Table 2 to evaluate the performance stability based on the type of liquid electrolyte used in the monolithic cells. In the first measurement, the monolithic cell containing HPEdominant electrolyte (i.e. cell B) shows the best performance with the value of $J_{s c}, V_{o c}, P_{\max }, F F$, and photoconversion efficiency of $1.28 \mathrm{~mA} / \mathrm{cm}^{2}, 0.62 \mathrm{~V}, 0.22$ $\mathrm{mW}, 0.26$, and $1.69 \%$, respectively. On the contrary, the HSE-dominant electrolyte cell (i.e. cell C) produce the poorest performance among all samples. In the first measurement, it can be seen from Table 2 that the $J_{s c}$ value of the HSE-dominant cell is significantly lower than the $J_{s c}$ value of the HPE-dominant cell that subsequently affects the maximum power of the cells. The value of $J_{s c}$ is affected by the charge diffusion velocity during the transport of the redox component [17]. Faster diffusion can be reached by the lower viscosity of the liquid electrolyte, which is possessed by AcN (HPE solvent), while the MePN (HSE solvent) has a significantly higher viscosity (see Table 2). In consequence, the HPE dominant cells have higher electrical conductivity that can produce high photoconversion efficiency compared to HSE dominant cell over the measurement.

Another noticeable result is shown by the $V_{o c}$ values, which are similar for all of the cells regardless the electrolyte type and remains slightly unchanged during the repeated measurements. In this case, there is evidence that the donor number of electrolyte solvent has a strong association with $V_{o c}$ value [24]. Referring to Table 2, there is a slight difference between donor number of $\mathrm{AcN}$ (HPE solvent) and MePN (HSE solvent) which are 14.1 and 16.1, respectively, so that the result of mixed solvent between AcN and MePN has a minor impact on yielded $V_{o c}$. Furthermore, $V_{o c}$ is known to be mainly determined by the fermi level energy of $\mathrm{TiO}_{2}$ versus the redox potential of the electrolyte. Since all of the electrolyte mixtures in this work contain the same redox mediators, i.e. $\mathrm{I}^{-} / \mathrm{I}_{3}^{-}$, it is well expected that the $V_{o c}$ will not vary significantly with the change in solvent compositions.

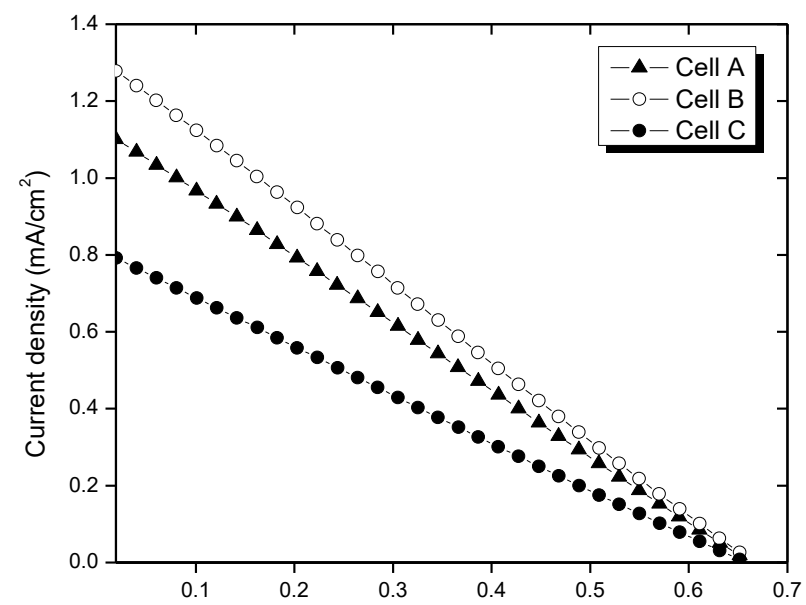

Figure 4. The I-V curves of monolithic cells measured at day 0 .
TABLE 3. THE PHOTOVOLTAIC PARAMETERS OF MONOLITHIC CELLS IN SIX TIMES MEASUREMENT.

\begin{tabular}{|c|c|c|c|c|c|c|}
\hline \multirow[b]{2}{*}{ Time } & \multirow[b]{2}{*}{ Sample } & \multicolumn{5}{|c|}{ Photovoltaic Parameter } \\
\hline & & $\left(\begin{array}{c}J_{s c} \\
\left(m /_{c m^{2}}\right.\end{array}\right)$ & $\begin{array}{l}V_{o c} \\
(V)\end{array}$ & $\begin{array}{c}P_{\max } \\
(\boldsymbol{m W})\end{array}$ & FF & $\begin{array}{c}\eta \\
(\%)\end{array}$ \\
\hline \multirow[t]{3}{*}{ Day 0} & Cell A & 1.10 & 0.65 & 0.19 & 0.26 & 1.50 \\
\hline & Cell B & 1.28 & 0.65 & 0.22 & 0.26 & 1.69 \\
\hline & Cell C & 0.79 & 0.65 & 0.13 & 0.25 & 1.05 \\
\hline \multirow[t]{3}{*}{ Day 4} & Cell A & 0.98 & 0.67 & 0.18 & 0.27 & 1.42 \\
\hline & Cell B & 1.17 & 0.67 & 0.22 & 0.28 & 1.73 \\
\hline & Cell C & 0.77 & 0.65 & 0.14 & 0.26 & 1.11 \\
\hline \multirow[t]{3}{*}{ Day 15} & Cell A & 0.59 & 0.61 & 0.11 & 0.30 & 0.88 \\
\hline & Cell B & 0.72 & 0.63 & 0.15 & 0.33 & 1.18 \\
\hline & Cell C & 0.51 & 0.61 & 0.10 & 0.31 & 0.76 \\
\hline \multirow[t]{3}{*}{ Day 22} & Cell A & 0.51 & 0.61 & 0.10 & 0.31 & 0.77 \\
\hline & Cell B & 0.63 & 0.63 & 0.13 & 0.33 & 1.03 \\
\hline & Cell C & 0.45 & 0.61 & 0.09 & 0.32 & 0.69 \\
\hline \multirow[t]{3}{*}{ Day 29} & Cell A & 0.56 & 0.63 & 0.11 & 0.30 & 0.85 \\
\hline & Cell B & 0.40 & 0.61 & 0.08 & 0.34 & 0.67 \\
\hline & Cell C & 0.42 & 0.61 & 0.08 & 0.32 & 0.67 \\
\hline \multirow[t]{3}{*}{ Day 35} & Cell A & 0.40 & 0.63 & 0.08 & 0.30 & 0.60 \\
\hline & Cell B & 0.32 & 0.65 & 0.07 & 0.32 & 0.52 \\
\hline & Cell C & 0.42 & 0.63 & 0.08 & 0.31 & 0.66 \\
\hline
\end{tabular}

Further investigation of the monolithic cells was conducted by measuring the incident photon-to-current conversion efficiency (IPCE). The spectra of IPCE plotted in Figure 5 reveals the performance of the monolithic cells in converting the absorbed photon into collected charge at the given wavelength which is in the visible range $(400-750 \mathrm{~nm})$. The value of IPCE was determined by the following formula [3]:

$$
I P C E=\frac{J_{s c}(\lambda)}{e \Phi(\lambda)}=\frac{J_{s c}(\lambda)\left[\mathrm{Acm}^{-2}\right]}{\lambda[\mathrm{nm}] P_{\text {in }}(\lambda)\left[W \mathrm{Wm}^{-2}\right]}
$$

The maximum measured IPCE value peaks at $55.6 \%$ at $520 \mathrm{~nm}$ was achieved by monolithic cell $\mathrm{C}$, followed by cell $\mathrm{A}$ and cell B which reach $53.9 \%$ at $540 \mathrm{~nm}$ and $51 \%$ at $540 \mathrm{~nm}$, respectively. In contrast to the I-V measurement results, the IPCE spectra indicate that cell $\mathrm{C}$ is more effective in generating electrons from the harvested light. During the regeneration process, the HSE-dominant electrolyte potentially can enhance the electron transfer from iodide to oxidized dye in a way to complete the photoelectric process. However, despite showing the lowest quantum yield, the HPE-dominant electrolyte is able to maintain the electron supply for ground state dye as it can manage the value higher than $50 \%$.

The photoconversion efficiency of the monolithic cells was plotted against the time of measurement to evaluate the degradation level of each cell as illustrated in Figure 6. The normalized curve version in Figure 7 is also provided to compare the stability of one cell to another more clearly. It is obvious that the performance of all cells gradually decreases over time. 


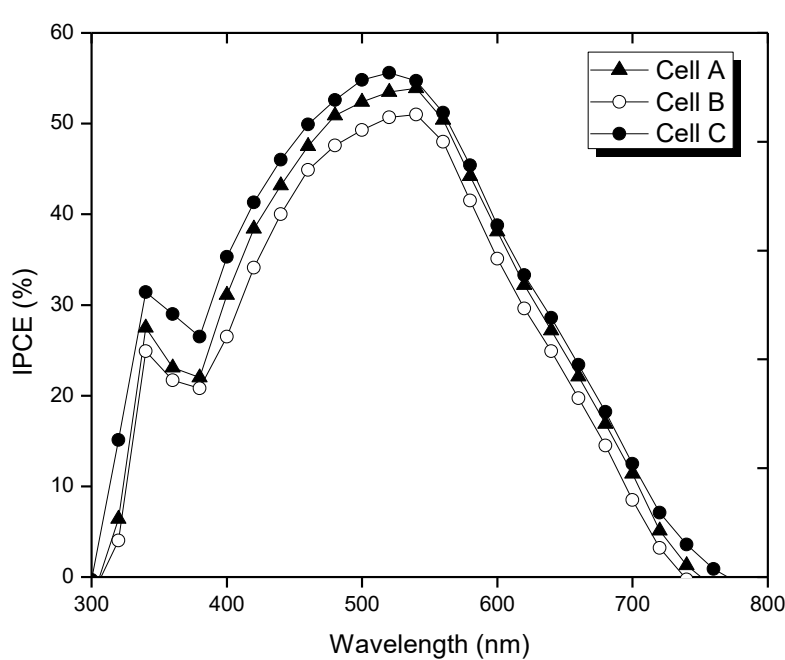

Figure 5. IPCE spectra for monolithic cells A, B, and C.

Initially, the cells were able to maintain the performance for 4 days, by having the efficiency not less than $1 \%$. The efficiency of each cell significantly drops on day 15 , which is assumed that the cells started to suffer from leakage and solvent evaporation. In the photovoltaic mechanism, the regenerated dyes receive electron supply from the redox couple of electrolytes to ensure the electron injection to semiconductor layer $\left(\mathrm{TiO}_{2}\right)$ works precisely to generate the high voltage. Therefore, the unexpected incident of liquid electrolyte that may occur can interfere the cycle of DSSC operation and diminish the power conversion efficiency. However, after day 15, the performance of the HSE-dominant cells (cell C) remains relatively stable until day 35 as it merely has a slight decrease within that time interval.

According to the entire I-V measurement result listed in Table 3, it has been shown that the HPE type electrolyte is able to enhance the performance of the cell at the outset and the HSE type electrolyte can maintain the monolithic cell stability. This circumstance is more likely influenced by the characteristic of each of their solvents. The lower boiling point of $\mathrm{AcN}$ and $\mathrm{VN}$ allow the electrolyte to easily evaporate or leak [19] which put their durability at risk. However, a mixture of both types of electrolytes in equal ratio (cell A) produces a solar cell

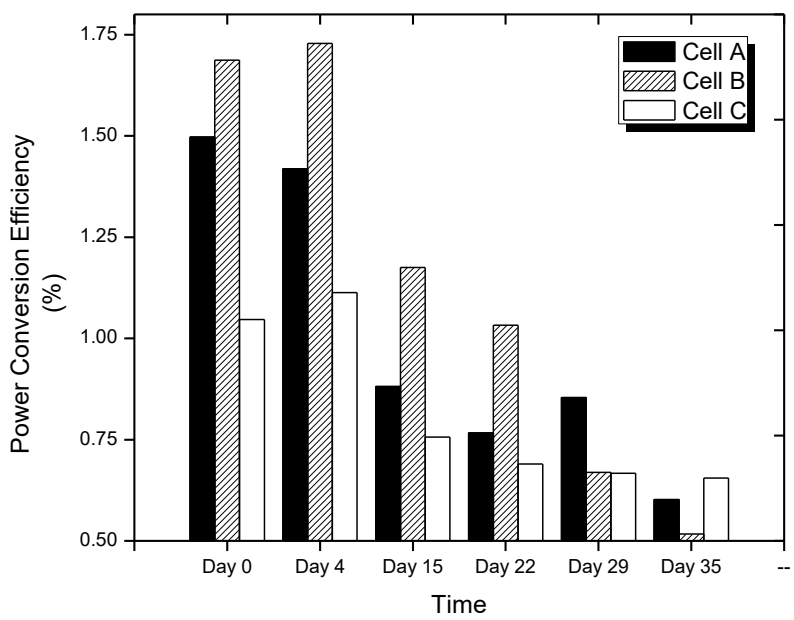

Figure 6. Comparison of photoconversion efficiency of various monolithic cells within 35 days.

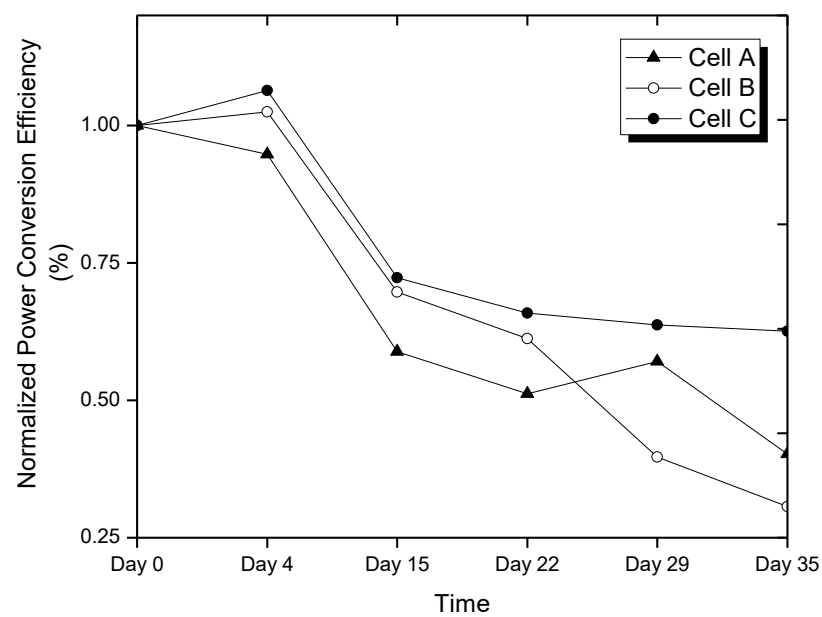

Figure 7. Stability curve as shown by the normalized photoconversion efficiency of various monolithic cells within 35 days.

device with the poorest performance in term of both photovoltaic parameters and stability.

Although the manual assembly of the cells can contribute to several errors during cell encapsulation, which possibly attribute to the quicker degradation of the cells, modifications of electrolytes in this work demonstrate that a balance of performance and stability can be achieved via simple combinations of electrolytes with different solvent properties.

\section{CONCLUSIONS}

The composition ratios between two types of commercial liquid electrolytes was varied to optimize the performance and stability of DSSCs with monolithic structure. It has been shown that the photovoltaic performance was highly affected by the liquid electrolyte component, particularly the type of solvent used in the electrolyte. In this work, monolithic DSSCs with liquid electrolyte containing acetonitrile and valeronitrile solvent showed the highest performance with photoconversion efficiency of $1.69 \%$, which is relatively high for monolithic DSSCs. However, the stability of the monolithic cells is still a major concern since all cells in this work shows performance degradation over time.

\section{ACKNOWLEDGMENT}

This work is financially supported by DIPA 2019 and INSINAS Ministry of Research, Technology, and Higher Education of the Republic of Indonesia. The entire experimental process and testing were conducted in Solar Cells Laboratory Research Center for Electronics and Telecommunications (P2ET) LIPI.

\section{REFERENCES}

[1] L. C. Andreani, A. Bozzola, P. Kowalczewski, and L. Liscidini, "Silicon solar cells: toward the efficiency limits," Advances in Physics: X, vol. 4, pp. 125-148, 2019.

[2] B. O'Regan and M. Grätzel, "A low-cost, high-efficiency solar cell based on dye-sensitized colloidal $\mathrm{TiO}_{2}$ films," Nature, vol. 353, pp. 737-740, 1991

[3] A. Hagfeldt, G. Boschloo, L. Sun, L. Kloo and H. Pettersson, "Dye-Sensitized Solar Cells," Chem. Rev., vol. 110, pp. 65956663,2010 
[4] J. Park and M. Lee, "Performance enhancement of dyesensitized solar cell with a $\mathrm{TiCl}_{4}$-treated $\mathrm{TiO}_{2}$ compact layer," Electronic Materials Letters, vol. 11, pp. 271-275, 2015.

[5] H. Choi, C. Nahm, J. Kim, S. Nam, D.-R. Jung and B. Park, "The effect of $\mathrm{TiCl}_{4}$-treated $\mathrm{TiO}_{2}$ compact layer on the performance of dye-sensitized solar cell," Current Applied Physics, vol. 12, no. 3, pp. 737-741, 2012.

[6] A. Sangiorgi, R. Bendoni, N. Sangiorgi, A. Sanson and B. Ballarin, "Optimized $\mathrm{TiO}_{2}$ blocking layer for dye-sensitized solar cells," Ceramics International, vol. 40, no. 7, pp. 10727 10735, 2014.

[7] L. Meng and C. Li, "Blocking Layer Effect on Dye-Sensitized Solar Cells Assembled with $\mathrm{TiO}_{2}$ Nanorods Prepared by dc Reactive Magnetron Sputtering," Nanoscience and Nanotechnology Letters, vol. 3, no. 2, pp. 181-185, 2011.

[8] P. N. Anggraini, N. M. Nursam, Shobih and J. Hidayat, "The effect of screen printed blocking layer on the performance of monolithic DSSC," in AIP Conference Proceedings, 2020.

[9] H. Y. Chen, S. R. Wang, H. Lin, G. Wang, S. H. Wang and G. J. Yang, "Stability of Dye Sensitized Solar Cells with Glass Frit Sealant," Key Engineering Materials, Vol. 1 ,2512-515, pp. 1619-1624, 2012.

[10] W. J. Lee, E. Ramasamy, D. Y. Lee and J. S. Song, "Glass frit overcoated silver grid lines for nano-crystalline dye sensitized solar cells," Journal of Photochemistry and Photobiology A: Chemistry, vol. 183, no. 1-2, pp. 133-137, 2006.

[11] S. Karuppuchamy, A. Andou and T. Endo, "Preparation of nanostructured $\mathrm{TiO}_{2}$ photoelectrode for flexible dye-sensitized solar cell applications," Applied Nanoscience, vol. 3, pp. 291293, 2013

[12] Y. Jun, J.-H. Son, D. Sohn and M. G. Kang, "A module of a $\mathrm{TiO}_{2}$ nanocrystalline dye-sensitized solar cell with effective dimensions," Journal of Photochemistry and Photobiology A: Chemistry, vol. 200, no. 2-3, pp. 314-317, 2008.

[13] Y. D. Zhang et al., "How to design dye-sensitized solar cell modules," Solar Energy Materials and Solar Cells, vol. 95, no. 9, pp. 2564-2569, 2011.

[14] A. Kay and M. Grätzel, "Low cost photovoltaic modules based on dye sensitized nanocrystalline titanium dioxide and carbon powder," Solar Energy Materials and Solar Cells, vol. 44, no. 1, pp. 99-117, 1996.
[15] A. Aslam et al., "Dye-sensitized solar cells (DSSCs) as a potential photovoltaic technology for the self-powered internet of things (IoTs) applications," Solar Energy, vol. 207, pp. 874892, 2020.

[16] M. E. Yeoh and K. Y. Chan, "A Review on Semitransparent Solar Cells for Real-Life Applications Based on Dye-Sensitized Technology," IEEE Journal of Photovoltaics, vol. 11, no. 2, pp. 354-361, 2021.

[17] J. Wu et al., "Electrolytes in Dye-Sensitized Solar Cells," Chemical Reviews, vol. 115, no. 5, pp. 2136-2173, 2015.

[18] N. Marinakis, M. Willgert, E. C. Constable and C. E. Housecroft, "Optimization of performance and longtermstability of p-type dye-sensitized solar cells with a cycloruthenated dye through electrolyte solvent tuning," Sustainable Energy Fuels, vol. 1, pp. 626-635, 2017.

[19] H. Iftikhar, G. G. Sonai, S. G. Hashmi, A. F. Noguera and P. D. Lund, "Progress on Electrolytes Development in DyeSensitized Solar Cells," Materials, vol. 12, no. 12, pp. 1-68, 2019.

[20] G. S. M. P. Ltd., "Great Cell Solar Materials,” 2020. [Online]. Available: https://www.greatcellsolarmaterials.com.

[21] N. M. Nursam, A. Istiqomah, J. Hidayat, P. N. Anggraini and Shobih, "Analysis of Catalytic Material Effect on the Photovoltaic Properties of Monolithic Dye-sensitized Solar Cells," Jurnal Elektronika dan Telekomunikasi, vol. 17, no. 2, pp. 30-35, 2017.

[22] R. Jiang, H. Michaels, N. Vlachopoulos and M. Freitag, "Beyond the Limitations of Dye-Sensitized Solar Cells," in Dye-Sensitized Solar Cells: Mathematical Modeling, and Materials Design and Optimization,dl Academic Press, 2019, pp. 285-323.

[23] N. M. Nursam, P. N. Anggraini, Shobih and J. Hidayat, "Lowcost monolithic dye-sensitized solar cells fabricated on single conductive substrate," in 2017 International Conference on Radar, Antenna, Microwave, Electronics, and Telecommunications (ICRAMET), 2017.

[24] J. Wu et al., "Progress on the electrolytes for dye-sensitized solar cells," Pure and Applied Chemistry, vol. 80, no. 11, pp. 2241-2258, 2008. 